\title{
ACADEMIA DO PEIXE FRITO: PRESENÇA DA INTELECTUALIDADE NO COTIDIANO POPULAR
}

\begin{abstract}
RESUMO
Em abordagem acerca da Academia do Peixe Frito como uma agremiação que congregava a intelectualidade literária de Belém, cuja intenção, além do prazer proporcionado pelo ambiente, era também a observação para a criação artística, este trabalho enfoca o Ver-o-Peso, não como uma feira para atividades comerciais, mas espaço plural e único, evidenciado em muitas obras; de efervescência cultural e confluência de classes sociais, onde se localizava essa Academia. Nossa hipótese é que a escolha do local não foi realizada de modo aleatório, mas em virtude da sua importância cultural para a cidade de Belém. Como suporte teórico tomou-se o pressuposto de Antonio Candido, no seu livro Literatura e Sociedade (2006), de que embora com semelhantes mentalidades, as pessoas se manifestam de diferentes formas, em decorrência das condições do meio social e cultural em que vivem, o que explica a variedade na criação, não só da literatura, mas também de todas as artes. Assim, aponta-se aqui o Ver-o-Peso como o porto de entrada e saída para muitas viagens, com registros de cenas da vida que acontece em Belém, numa demonstração de sua importância para a representação cultural dessa cidade. Nesse sentido, elaborou-se um percurso histórico do espaço e da Academia do Peixe Frito, levando-se em conta sua relevância no contexto social, para dar continuidade à tradição cultural, já que essa atitude proporcionará a aproximação do artista em relação à vivência que poderá ser focalizada em sua obra.
\end{abstract}

Palavras-chave: Literatura; Ver-o-Peso; Academia do Peixe Frito.

\begin{abstract}
In approach on the Academia do Peixe Frito as a whole, which brought together the literary intelligentsia of Belém, whose intention, beyond the pleasure provided by the environment, was also the observation for artistic creation, this work also takes into consideration the Ver-o-Peso, not only seen as a market for commercial activities, but plural and unique space, evidenced in many works; of cultural effervescence and confluence of social classes, where was located this academy. Our hypothesis is that the choice of location was not carried out randomly, but because of its cultural importance to the city of Belém. As a theoretical support was taken the assumption of Antonio Candido, in this book Literature and Society (2006), although with similar mentalities, people who manifest themselves in different ways as a result of the conditions of the social and cultural environment in which they live, which explains the variety in the creation, not only of the literature, but also of all the arts. Therefore, it is pointed out here the Ver-o-Peso as the port of entry and departure for many trips, with records of scenes from the life that takes place in Belém, in a demonstration of their importance to the cultural representation of this city. In this sense, was elaborated a historical journey of space and that of Academia do Peixe Frito, taking into account their significance in the social context, in order to continue the cultural tradition, since this will provide the approach of the artist in relation to the experience that can be focused on his work.
\end{abstract}

Keywords:Literature; Ver-o-Peso; Academia do Peixe Frito.

.




\section{INTRODUÇ̃̃O}

A partir da discussão lançada por Antonio Candido, em seu livro Literatura e Sociedade, acerca da atuação dos fatores sociais na construção de uma obra literária, levando-se em conta "o fato da arte ser, eminentemente, comunicação expressiva, expressão de realidades profundamente radicadas no artista, mais que transmissão de noções e conceitos" (CANDIDO, 2006, p. 31), considera-se neste trabalho o meio em sua essência maior, como a representação da própria vida que se desenvolve em ambiente social, em todos os seus sentidos, distante de uma lógica intelectual, mas que por esta é captado pelo artista como uma fonte de reflexão, que lhe nutre para o trabalho de criação das suas obras.

Sob o ponto de vista sociológico do crítico que, contrapondo-se à distinção da arte pela diferenciação estabelecida em duas categorias, ao que denominou arte de agregação e arte de segregação, há necessidade de uma intervenção efetiva, no sentido de que o homem de hoje conserva "lado a lado o mágico e o lógico, fazendo ver que, ao menos sob este aspecto, as mentalidades de todos os homens têm a mesma base essencial" (CANDIDO, 2006, p. 53). Por isso, torna-se válida a mediação entre essas duas categorias, levando-se em conta as singularidades de cada uma.

Ainda nessa perspectiva, Antonio Candido aponta para o risco que esse posicionamento pode ocasionar, já que a agregação se dá pela junção de experiências coletivas, com fins comunicativos acessíveis, utilizando-se do que já está estabelecido socialmente, sendo uma possibilidade de ampliação para a recepção da arte literária. Por outro lado, a segregação, mais voltada à renovação do sistema simbólico e recursos expressivos, restringe os mecanismos implicados na produção de uma obra e, consequentemente, o número de receptores. Assim, a matéria abstraída do meio para a criação artística e a forma da obra literária concluída "dependerão em parte da tensão entre as veleidades profundas e a consonância ao meio, caracterizando um diálogo mais ou menos vivo entre criador e público" (CANDIDO, 2006, p. 84).

Portanto, a questão levantada neste trabalho está voltada ao surgimento da Academia do Peixe Frito, enquanto congregação de intelectuais, criada no Ver-o-Peso, espaço de encontro de toda a diversidade existente na cidade de Belém.

\section{VER-O-PESO DA HISTÓRIA DE BELÉM}

Conforme o portal do Instituto do Patrimônio Histórico e Artístico Nacional - IPHAN, a história da feira do Ver-o-Peso iniciou-se em 1625, nove anos após a fundação de Belém, tornando-se, ao longo do tempo, um dos símbolos representantes da própria história da cidade, recebendo, no ano de 1977, a elevação a um conjunto arquitetônico e paisagístico.

A feira livre, surgida timidamente à margem direita da desembocadura do igarapé do Piri com a baía do Guajará, logo foi se espalhando pelos arredores da casa de "Haver o Peso", posto destinado à aferição de mercadorias e arrecadação de impostos. É o mais antigo logradouro público que acompanhou o crescimento da cidade, expandindo-se também, integrando-se a ela, a ponto de receber na Belle Époque, momento de grande desenvolvimento econômico e social, as imponentes edificações de ferro, mantidas até hoje, construídas de forma semelhante àquelas que haviam na Europa, sobretudo na França, cuja capital tornou-se modelo ao ambicioso projeto de urbanização de Belém, que passava pelo apogeu de sua riqueza. Essa condição, proporcionada pelo crescimento de uma economia baseada na produção da borracha trouxe maior aproximação desta cidade aos principais centros europeus, pois era mais fácil chegar à Lisboa do que ao Rio de Janeiro, a capital brasileira naquele período.

Ponto de entrada e saída da cidade, o Ver-o-Peso logo passou a ter grande comércio e fluxo de frequentadores com intenção diversa, sendo palco de muitos acontecimentos marcantes na história de Belém. Foi o porto de embarque para Pedro 
do domínio português na Amazônia Ocidental.

Ainda no primeiro século de fundação da cidade, mais precisamente no ano de "1653, o padre Antônio Vieira aportou no Ver-o-Peso, chegando a Belém para suas lides missionárias em defesa da liberdade dos índios” (UFPA, 2013?, s.p.). Assim, o Ver-o-Peso foi porto para o ilustre padre que, além do seu empenho na missão catequética, contribuiu para a literatura com inúmeros de seus sermões que enfocavam aspectos da vida em nossa região, sobretudo em relação aos índios e negros escravizados.

\title{
VER-O-PESO DA ARTE LITERÁRIA PARAENSE
}

Além de feira onde acontece a venda e a troca de mercadorias diversas, o Ver-o-Peso é também local de convergência para toda a diversidade que forma $o$ povo. Esse espaço logo foi adicionado ao cotidiano da cidade, agregando hábitos e costumes que foram incorporados, tornando-se característicos do povo de Belém. " $\mathrm{E}$ tamanha foi a sua influência que ainda hoje assinala, não mais uma Casa de Imposto, porém, uma área tradicional da cidade" (CRUZ, 1952, p. 69). Essa aproximação oportunizou o surgimento da inspiração criativa para muitos artistas.

Em múltiplas formas de percepções, o Ver-o-Peso é fonte inesgotável para aqueles que se dedicam à arte, tendo, além da feira, um porto ideal para início e fim de viagens ao mundo da imaginação.

\begin{abstract}
Bem sabemos que a feira do Ver-o-Peso, ou a impressionante paisagem de sua doca fluvial, ainda está à espera de um escritor, de um romancista, principalmente amazônico, que venha dar forma literária ou ambiência folclórica ao rico e opulento material humano que ela oferece ao pesquisador. (MENEZES, 2011, p. 49/50)
\end{abstract}

Em O Missionário, obra de Inglês de Sousa, o Ver-o-Peso é mostrado na lembrança do Padre Antônio de Morais, personagem principal, que lá desembarcou ainda menino, do barco do padrinho que o levou para o seminário. Do tempo que passou em Belém, antes de ser designado para trabalhar em Silves, uma localidade do interior paraense, guardava muitas recordações, valendo ressaltar a descrição de um fim de dia, quando o burburinho reduz com a volta para casa de muitos trabalhadores, mostrado de forma bem naturalista como o título que lhe fora atribuído por alguns críticos, de iniciador desse movimento literário no Brasil:

Negras da Costa, com as panelas de tacacá e de quibebe, equilibradas sobre as rodilhas de riscado, que em forma de turbante lhes cingiam a carapinha, passavam, balançando os quadris num descadeiramento ridiculo, e enchendo o ar de forte catinga suarenta, que se misturava ao aroma irritante do trevo e da manjerona exalado pelo penteado das mulatas, e ao pixé nauseabundo do Ver-o-Peso. (SOUSA, 1992, p. 165)

Também foi porto de chegada para Alfredo, protagonista dos romances que compõem o ciclo do Extremo Norte, de Dalcídio Jurandir. O personagem, ainda menino, iniciou sua saga em Cachoeira do Arari, no romance Chove nos campos de Cachoeira, sonhando com a possibilidade de sair de lá para uma outra vida, tão gigantesca quanto o caroço de tucumã que comportava toda sua ambição de conhecer um mundo maior, representado por Belém, a grande capital do Estado, símbolo instigante de uma urbanidade criada em sua imaginação, que só aconteceu no romance Belém do Grão Pará. Na ânsia de menino desbravador que desejava explorar a nova terra, a cena descrita mostra o custoso desejo dessa realização, mesmo após a chegada. Nada mais o afligia que o prazer e "o encanto daquela demora. Tudo custava. Custou a manobra do barco para entrar no Ver-o-Peso, o cais das embarcações a vela que vinham do Guamá, Ilhas, Salgado, Marajó, Tocantins, Contra-Costa..." (JURANDIR, 2016, p. 37). 
Outro desembarque literário é o da personagem anônima de Maria Lúcia Medeiros, no livro Velas. Por quem?, que, por uma narrativa sem identificação do porto, também pode ser indicação a tantos outros em cidades do interior paraense. Mas a hipótese de ser o Ver-o-Peso está confirmada pelos indícios de ser a chegada da menina interiorana que vem para a capital em busca de uma vida melhor. Contrapondo-se às expectativas da jovem personagem que alimenta a ilusão de minimizar seus sofrimentos com uma vida diferente daquela vivida no interior, há na narrativa um lamento pelo engano:

Ao saltares dessas águas barrentas, ao abandonares sem saudade, rápido se perdeu o teu barco entre os tantos aportados naquele cais. Fatal foi tropeçares e seguires aos solavancos pelas ruas achando que eram de boas-vindas os olhares. Ao pé do casarão mal iluminado fatal foi pensares que ofereciam vida nova, pois ouviste os sinos. (MEDEIROS, 1990, p. 11)

Porto de idas e vindas, local de muitas trocas, até mesmo de ideias, o Ver-o-Peso é um espaço propício para encontros e confraternizações de qualquer natureza. Vale ressaltar ainda Max Martins, em sua expressão poética, que no poema "Ver-o-Peso" elaborou um intrigante jogo de palavras, de forma simples como as vidas que ali se encontram, indicativo de representações do espaço em relação à trajetória de toda vida humana, com ações convergentes para o mesmo fim a que todos nós estamos sujeitos, como se pode observar nas estrofes abaixo:

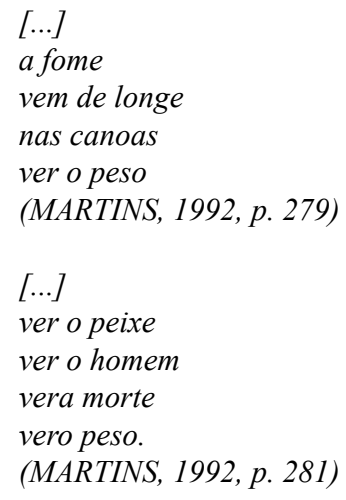

É nesse local eclético, de congraçamento do povo, propício à intersecção da diversidade, que se realizam encontros sem restrições a etnias, classes, credos e ideias. É um espaço focalizado em prosa e verso, onde acontecem diálogos (des) pretenciosos, de muitos olhares e ouvidos atentos, inebriados pela brisa quente, que sopra às narinas o cheiro do peixe frito ali vendido. Foi nesse ambiente, mais precisamente no bar Águia de ouro, o marco inicial das reuniões de um grupo de intelectuais que se intitularam os acadêmicos do Peixe Frito.

\section{VER-O-PESO DOS DISSIDENTES}

O poderio econômico decorrente do ciclo da borracha, iniciado na segunda metade do século XIX, trouxe mudanças significativas à estrutura urbana de Belém, modificando também o modo de vida de sua população, repercutindo mesmo depois de baixada essa febre, com uma evidente divisão da sociedade. De um lado os mais abastados, ainda procurando satisfazer o prazer de frequentarem os requintados cafés, alimentavam as lembranças de uma riqueza perdida com o declínio da produção gomífera; de outro, os que pouco usufruíram daquele período áureo procuravam alternativas mais acessíveis ao seu poder aquisitivo.

A queda econômica também repercutiu entre os intelectuais que, em 1921, apesar dos interesses comuns, dividiram-se em dois grupos; um representante da elite social, reconhecido como Academia ao Ar Livre, que passou a encontrar-se no 
terraço do Grande Hotel, como esclarece Raul Bopp: “A noite, no terraço do Grande Hotel, debaixo de copadas mangueiras, reuniam-se os grupos habituais. $\mathrm{O}$ círculo de conhecidos ia alargando-se" (BOPP, 1968, p. 221 apud FIGUEIREDO, 2012, p. 47). Nesses encontros, as discussões giravam em torno de "tudo. Entravam em comentários os fatos correntes, fofocas e anedotas. Agitavam-se opiniões, notadamente no campo literário. Em geral, os modos de ver, nesses assuntos, arrematavam-se em blagues" (FIGUEIREDO, 2012, p. 47).

De origem modesta e condições econômicas pouco favoráveis a gastos excessivos, o outro grupo, liderado por Bruno de Menezes, recusou-se a participar de tais reuniões, o que lhe parecia contrário aos ideais que defendia. Engajado em movimentos políticos, o poeta posicionava-se ao lado dos menos favorecidos, alertando-os para uma efetiva participação em sindicatos e cooperativas. Depois de seu envolvimento com o "universo anarquista, o poeta tornara-se crítico da sofisticação dos encontros literários em cafés à moda parisiense, porém isso nunca impediu que houvesse uma constante interação entre as duas rodas" (FIGUEIREDO, 2012, p. 48). Embora as reuniões dos grupos fossem separadas, o rompimento não foi definitivo, havendo encontros frequentes, com a participação de alguns membros do grupo opositor, o que indicava a aproximação e troca de informações.

\section{A ACADEMIA DO PEIXE FRITO}

Com Bruno de Menezes à frente, o grupo opositor à Academia ao Ar Livre passou a frequentar o Ver-o-Peso, local indistintamente acolhedor de todas as pessoas, criando-se então a APF (Academia do Peixe Frito), um nome bem apropriado ao aprazível espaço onde havia, e ainda hoje há uma variedade de barracas de venda de comidas diversas, sendo a especialidade de todas o peixe frito. Naquela área, sempre "se encontram turistas e literatos, pessoal de teatro, viajantes, em visita à feira; algum grupo de boêmios decadentes, que sonharam a "Academia do Peixe Frito" (MENEZES, 2011, p. 80). Essa idealização não ficou apenas no sonho, mas uma realização que aconteceu em 1921, e permaneceu por algumas décadas.

De início, os seguidores de Bruno de Menezes, segundo Alonso Rocha, foram: Abguar Bastos, Paulo Oliveira, De Campos Ribeiro, Jacques Flores, Nuno Vieira, Muniz Barreto, Sandoval Lage, Clóvis de Gusmão, Orlando de Moraes, Lindolfo Mesquita, Ribeiro de Castro e Rodrigues Pinagé, frequentadores assíduos da Academia, além Antonio Tavernard e Ernani Vieira que, por motivo de doença, não participavam dos encontros noturnos (1994, p.14).

Símbolo daqueles intelectuais boêmios, o Peixe Frito, servido em postas acompanhadas de farinha d'água e doses de cachaça, transformou-se em nome de uma academia que, semelhante à Academia ao Ar Livre, em suas reuniões "debatia literatura e equacionava revoluções, captando a simpatia do povo, nos bares e cafés, nas festanças do Umarizal e outros subúrbios, onde se tornavam reis, como oradores e poetas" (idem). Não haveria outro ambiente tão apropriado quanto o Ver-o-Peso, espaço mais representativo da diversidade de Belém, em todos os seus aspectos, descrito por Bruno de Menezes como um...

...vivido cosmorama de fisionomias de todas as mestiçagens, a mistura, indiferente, das classes sociais, o cenário colorido do mulherio, desde as senhoras brancas, as serviçais de sangue mesclado, as "nigrinhas" dengosas, as cozinheiras pretas e mulatas, as crioulas e caboclas, - este aglomerado de feições indescritíveis, de pregões, de falario, era inteiramente familiar à nossa retina. (MENEZES, 1993, p. 141)

Ao atribuir a denominação de "vívido cosmorama", o poeta revela o que essa feira realmente é: um aglomerado de feições diversas que formam um complexo mosaico. Não haveria melhor representação de acolhimento para tantas culturas e etnias, que juntas formam uma cultura singular; motivo de obras criadas por muitos artistas.

VOL. 15 | N.1 | JUL. 2018 ISSN 1415-7950

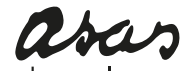

da palavra 
Dos botecos frequentados pelo grupo, o bar Águia de Ouro era o preferido, onde, em 1955, iniciou-se a realização da festividade de São Benedito da Praia. "No ano de 1955, a 10 de novembro, com a imagem de São Benedito instalada no seu nicho no bar 'Águia de Ouro', num grupo de feirantes que se achavam 'alegres', alguém se lembrou de fazer uma 'folia' em honra do 'santo da praia"' (MENEZES, 2011, p. 69). Semelhante ao que diariamente acontecia na feira, essa festividade era um misto profano-religioso, que ali aconteceu pela iniciativa de Fernando Alberto Leal, um ambulante apelidado de "Carrão", que com um "mastro" confeccionado com cipós e folhagens sobradas das bancas de ervas, saiu "na 'ginga' e na 'onda', cantando toadas populares dedicadas a São Benedito. Bastou isto para que se improvisasse a primeira 'folia', da qual resultaria a lembrança e a continuação da festividade" (MENEZES, 2011, p. 69).

A estreita relação entre Bruno de Menezes e o Ver-o-Peso trouxe ao poeta a inspiração para uma criação diversa. Frequentador assíduo da feira e, sobretudo dos bares do Ver-o-Peso, Bruno de Menezes já estava familiarizado com o local, antes mesmo da formação da Academia do Peixe Frito, pois, em suas visitas, em meio à agitação de uma cidade viva, que se via ali representada, entregava-se ao prazer da observação, em todos os seus aspectos, desde cedo, ainda de madrugada.

\begin{abstract}
E desde quando alvorece, o infatigável cotidiano, no ciclo das mesmas horas, aquele recanto da famosa feira do Ver-o-Peso reproduz, coro num filme de contínua metragem, o mesmo cenário habitual, sempre novo e envolvente, em qualquer época do ano, até nas estações das chuvas copiosas e das marés de lua, que alagam inteiramente essa área, ao galgarem e invadirem a rampa, para divertimento da caboclada, otimista e satisfeita com a sua vida sem ambições nem problemas. (MENEZES, 2011, p. 82)
\end{abstract}

Absortos pelo movimento constante, os membros da nova academia lançavam-se a discussões de assuntos diversos, inclusive da literatura. Mas o que mais despertava a atenção dos acadêmicos era a vida simples que ali se passava.

Separados apenas por questões econômicas, mas com os mesmos ideais no campo da literatura, os dois grupos continuavam a manter contato. Vez por outra, as academias revezavam seus membros, havendo ainda encontros em locais neutros, distantes do Ver-o-Peso e do Grande Hotel; um deles era a garagem do Clube do Remo, nome dado à sede náutica daquele clube, onde também era servida uma boa peixada. "Foi, portanto, numa espécie de encontro dessas duas turmas que surgiu, ainda em 1921 a Associação dos Novos" (FIGUEIREDO, 2012, p. 48). Essa associação logo foi apelidada por Bruno de Menezes como "Vândalos do Apocalipse" e, com o lema "destruir para criar", semelhante à proposta antropofágica dos intelectuais participantes da semana de arte moderna que deu início ao modernismo brasileiro, propunha uma mudança radical. "E era exatamente isso que a nova tribo paraense queria seguir - derrubar os monumentos da literatura e das artes" (FIGUEIREDO, 2012, p. 48).

Embora houvesse a proposta de unificação dos grupos, as reuniões da Academia do Peixe Frito ainda aconteciam no Ver-o-Peso, agregando-se a ela, mesmo de forma esporádica, novos membros como o ilustre escritor Dalcídio Jurandir, que no prefácio de seu premiado livro Chove nos campos de Cachoeira, publicado em 1941, faz menção ao peixe frito como um símbolo em torno do qual a vida na cidade acontece e literatura paraense se movimenta.

No vem e vai que a vida encerra, as reuniões tornaram-se mais difíceis, sobretudo depois do falecimento de Bruno de Menezes e, mais tarde, com o fechamento do bar Águia de Ouro, também em decorrência do falecimento do seu dono. Mas o Ver-o-Peso continua acolhedor, como centro convergente de tantas culturas que se espalham por outros recantos da cidade. Piry, Mercado do Peixe, Feira do Ver-o-Peso, Solar da Beira e Mer- 
cado da Carne, território de São Benedito da Praia. Contexto histórico-geográfico da península do Guamá e ilhas do Marajó-Guajará. Cerne da amazonidade. (VARELA, 2018, s.p.)

Abrigo para todas as etnias, todos os credos e culturas que se uniram para formar essa cidade; o Ver-o-Peso é uma frondosa árvore de raízes fincadas em solo fértil. Em toda a sua extensão, o cheiro do peixe frito entranha-se nos quadros, nos livros, nos palcos que representam as vidas que por ali passam.

Com certeza, no mundo encantado da memória a antiga e eclética confraria de São Bendito da Praia está a festejar com foguetes, mastro votivo e batuque celestial as boas novas da Academia do Peixe Frito, na virada de 2014 para 2015 rumo aos 400 anos de Feliz Lusitânia. (VARELA, 2014, s.p.)

\section{CONSIDERAÇÕES FINAIS}

Ao iniciar este trabalho com a intenção de abordar a Academia do Peixe Frito como um espaço de encontro e criação literária, observou-se um horizonte mais amplo, no qual essa Academia está inserida, presente na criação literária de muitos autores paraenses.

Pela demonstração do espaço, considerado como elemento de composição da obra literária, torna-se pertinente a compreensão de que a grandeza das manifestações literárias está na elaboração de um sistema simbólico acerca do meio, de forma intemporal e universal, já que tanto o tempo quanto o meio, são fatores que nessas manifestações não estão vinculados a um determinado rigor do momento e nem do lugar.

Dessa forma, com a exaltação do meio pelas faculdades poéticas que representam aspectos da vida simples, elevados à imaginação de uma fantasia, abre-se a perspectiva para a entrada, pela leitura, nesse universo transfigurado, mas que está dentro de uma realidade possível, captada e manipulada pelo autor em sua obra. Estabelece-se assim uma relação com fatores básicos da cultura de um meio, numa abordagem da estrutura econômica, política e social.

Portanto, cria-se então a validade para a iniciativa de revitalização do espaço do Ver-o-Peso, por ser não apenas um ponto referencial da cidade de Belém do Pará, mas um porto de chegada e saída para viagens imaginárias; a porta de entrada de qualquer cidade localizada à beira de um rio, que dá acesso a uma grande feira como tantas outras pelo mundo afora. Isso possibilitará a percepção do espaço como a impressionante paisagem de uma doca fluvial à espera de alguém que lhe dê forma literária, como afirmou o poeta Bruno de Menezes; percepção reforçada com o pensamento do renomado folclorista Luís da Câmara Cascudo de que o autor, enquanto intelectual, é capaz de transformar em obra da literatura as memórias populares. "Ao lado da literatura, do pensamento intelectual letrado, correm as águas paralelas, solitárias e poderosas, da memória e da imaginação popular" (CÂMARA CASCUDO, 1986, p. 15), e é essa água que banha a doca do Ver-o-Peso, jorrando como fonte alimentadora da capacidade criativa do artista, que se apresenta com toda a magia existente no contexto social, para a elaboração de suas obras.

\section{REFERÊNCIAS}

CANDIDO, Antonio. Literatura e Sociedade. Rio de Janeiro: Ouro sobre azul, 9a ed. 2006.

CÂMARA CASCUDO, Luís da. Contos tradicionais do Brasil. Belo Horizonte/São Paulo: Itatiaia/EDUSP, 1986. 
Augusto Henrique) - disponível:https://issuu.com/ufpadoispontozero/docs/procissao-dos-seculos/vultos-e-episodios-da-historia. - Acesso em: 18/04/2018

FIGUEIREDO, Aldrin Moura de. Os vândalos do apocalipse e outras histórias: arte e literatura no Pará dos anos 20. Belém: IAP, 2012.

INSTITUTO DO PATRIMÔNIO HISTÓRICO E ARTÍSCO NACIONAL (IPHAN) - Ver-o-Peso (Pa) - Disponível em: http://portal.iphan.gov.br/pagina/detalhes/828 - Acesso em: $19 / 04 / 2018$.

JURANDIR, Dalcídio. Belém do Grão-Pará. 4a edição. Belém: Marques Editora, 2016.

MARTINS, Max. Não para consolar: poemas reunidos 1952-1992. Belém: Cejup, 1992.

MEDEIROS, Maria Lúcia. Velas. Por quem? Belém: CEJUP, 1990.

MENEZES, Bruno. Bailado Lunar \& São Benedito da Praia. Belém: Diário do Pará, 2011.

. Obras completas de Bruno de Menezes. Vol. 2. Belém: Secretaria Estadual de Cultura

- Conselho Estadual de Cultura, 1993.

ROCHA, Alonso [et al]. Bruno de Menezes ou a sutileza da Transição: Ensaios. Belém: CEJUP, Universidade Federal do Pará, 1994.

SOUSA, Inglês. O Missionário. $3^{\text {a }}$ edição. São Paulo: Ática, 1992. Disponível em: http:// www.dominiopublico.gov.br/download/texto/bv000120.pdf - Acesso em: 21/04/2018.

UNIVERSIDADE FEDERAL DO PARA (UFPA) - O mercado e a cidade de Belém -Disponível em: http://www.ufpa.br/cma/verosite/historico.html - Acesso em: 19/04/2018.

VARELA, José Marajó. Caderno de aprendiz na universidade da maré. Belém, 2014.

Disponível em:

http://republicaveropeso.blogspot.com/2014/12/academia-do-peixe-frito-bem-cultural-de. html. Acesso em 19/04/2018.

Caderno de aprendiz na universidade da maré. Belém, 2018. Disponível em: http:// republicaveropeso.blogspot.com.br/2018/02/sintese-provocativa-academia-do-peixe.html. Acesso em: 19/04/2018.

Novos, 1946-1952. Campinas, SP, 2003.

É estudante de doutorado, com formação na área de concentração dos Estudos Literários do Programa de Pós-graduação da Universidade Federal do Pará, com pesquisa focada nas relações de poder expressas na obra de Bruno de Menezes. Possui graduação em Psicologia e Letras, com habilitação em Língua Portuguesa e Língua Francesa. Atualmente exerce a atividade de professor do Ensino Médio, na Secretaria de Educação do Estado do Pará. http://orcid.org/0000-0003-4723-8617. E-mail: pereira.edvaldo56@gmail.com 